\title{
Article
}

\section{How and why people are impolite in danmu?}

Wang, Jiayi

Available at http://clok.uclan.ac.uk/34110/

Wang, Jiayi ORCID: 0000-0003-2720-8218 (2020) How and why people are impolite in danmu? Internet Pragmatics, 2 (1). ISSN 2542-3851

It is advisable to refer to the publisher's version if you intend to cite from the work. http://dx.doi.org/10.1075/ip.00057.wan

For more information about UCLan's research in this area go to http://www.uclan.ac.uk/researchgroups/ and search for < name of research Group>.

For information about Research generally at UCLan please go to http://www.uclan.ac.uk/research/

All outputs in CLoK are protected by Intellectual Property Rights law, including Copyright law. Copyright, IPR and Moral Rights for the works on this site are retained by the individual authors and/or other copyright owners. Terms and conditions for use of this material are defined in the policies page.

\section{CLoK}

Central Lancashire online Knowledge www.clok.uclan.ac.uk

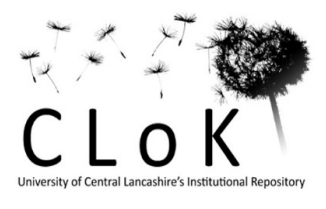


Wang, Jiayi (2020) How and why people are impolite in danmu? Internet Pragmatics, 2 (1).

Official URL: https://doi.org/10.1075/ip.00057.wan

\title{
How and Why People Are Impolite in Danmu
}

\section{Jiayi Wang}

\begin{abstract}
This study explores how and why people are impolite in danmu. Danmu refers to anonymous comments overlaid on videos uploaded to video-sharing sites. Although there is wide recognition that impoliteness prevails in danmu, the questions of how and why people are impolite in this context have rarely been investigated. This study addresses this lacuna of research. Using both an analysis of comments identified as impolite by participants and an analysis of focus group interview data, this research identified seven impoliteness strategies, covering both conventionalised formulae and implicational impoliteness. By applying uses and gratifications theory, this study identified five uses and gratifications for performing impoliteness in danmu: social interaction, entertainment, relaxation, expression of (usually differing) opinions and finding connections. The dialectic of resonance and opposition that emerged from the data helped explain why impolite comments tended not to be perceived as inappropriate in danmu. Thus, this study contributes to the emerging research on impoliteness in social media.
\end{abstract}

Keywords: danmu, impoliteness, uses and gratifications theory, implicational impoliteness, conventionalised formulae, dialectic of resonance and opposition, video sharing

\section{Introduction}

The social media revolution within the last decade has fundamentally shifted the internet towards user-driven technologies, such as video-sharing platforms, which have become hugely popular and widely influential. Yet, despite their popularity and influence, for linguists, video-sharing sites such as YouTube remain "an extremely important and largely unexplored terrain" (Johansson 2017: 191). This is especially the case for danmu-enabled video-sharing platforms. The word danmu (弹幕) literally means “bullet curtain/screen”, and 
it originally referred to a barrage in military usage. Danmu videos, originating from the Japanese word “danmaku (弾幕)", were introduced by the Japanese anime video website NicoNico Douga in 2006; they appeared in China in 2008 (Tan and McNeilly 2017; Zhang and Cassany 2019a). Dапти refers to (1) a video comment sharing system in which viewers can insert comments directly on top of an uploaded video or (2) comments created under this system. In danmu, viewers can simply pause and post comments during any specific moment in the video, and the comments will overlay the screen in real-time, usually by 'flying' across the screen from right to left like bullets, as shown in the screenshot below.

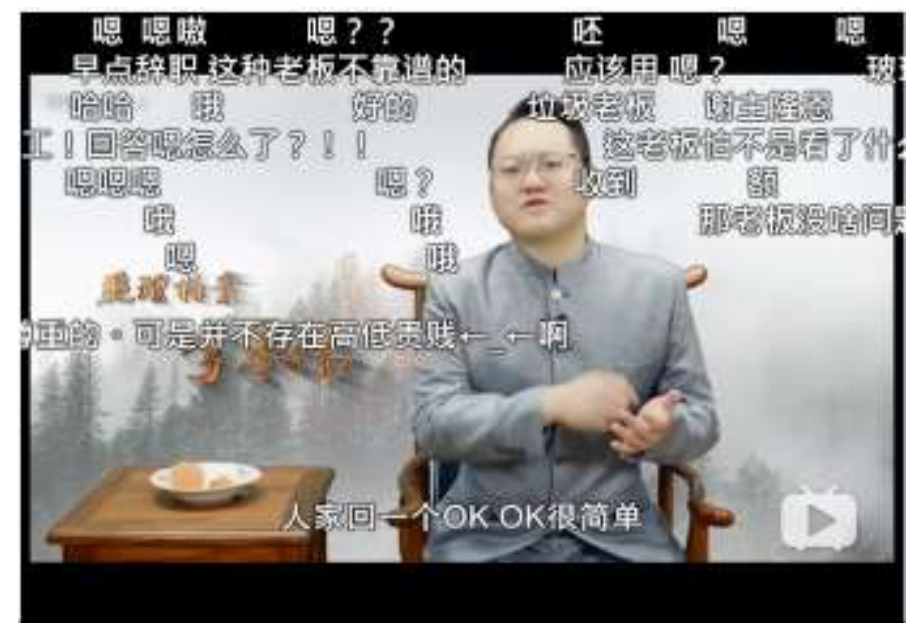

Figure 1. A danmu screenshot

The essential difference between danmu comments and YouTube comments is the superimposition of time and space and anonymity; that is, danmu enables users to superimpose anonymous comments on a video, and the comments are displayed in synchronicity with that particular video frame in subsequent viewings. Rather than scrolling down to read the comments section, as is done on video-sharing sites such as YouTube, the function of danmu, or overlaid comments on mainstream Chinese video-sharing sites such as Bilibili and iQiyi, is to make watching online videos more interactive (Liu, Suh and Wagner 2016) and more gratifying (Chen, Gao, Rau and Chen 2015) than traditional commentary systems. While danmu did not appear in China until 2008, its social appeal has increased exponentially, particularly over the past few years. For example, the largest Chinese videosharing site featuring dапти, Bilibili, is one of the three most visited video-sharing sites in China, and ranks 35th in terms o $\neq$ f global internet engagement (Alexa 2019).

It has been widely recognised that linguistic impoliteness prevails in danmu, and the literature on the subject reflects this (Feng 2018; Zhang 2015), but the question of how and why people 
are impolite in danmu has rarely been studied. This study addresses this gap. In the following sections, the paper first presents a literature review on impoliteness, explicating gaps in the literature regarding danmu; it then explicates how uses and gratifications theory can be used to analyse danтu. Next, the paper describes the dataset and the methods used in the study. The findings regarding how and why people express impoliteness in danmu are reported. The discussion relates the findings to the existing literature. The paper concludes with this study's major contributions.

\section{Impoliteness and danmu}

Impoliteness in Chinese interaction is largely underexplored. Researchers have mainly studied face-to-face interaction. Social variables such as age, rank and the distinction between inside and outside relations (内外有别 nei wai you bie) have been identified as playing important roles in impoliteness performance and perception (Wang 2019). For example, Pan and Kádár (Pan 2000; Pan and Kádár 2011) found that in Chinese service encounters in staterun department stores up until the 1990s, a lack of politeness was widely observed in 'where the shop assistant did not know the customer personally; this was in sharp contrast to 'inside relations' where the shop assistant and the customer knew each other personally.

Online interaction may differ from face-to-face interaction. For example, the influencing factors identified above — such as knowing each other personally—seem to be obscured in the virtual world. Researchers have characterised commenters on social media as 'networked audiences' (Marwick and Boyd 2011; Tagg, Seargent and Brown 2017) who may engage in discussions without knowing each other, and who remain unfamiliar to each other, such as in the context of YouTube and Twitter comments.

Impoliteness online is not uncommon, and extreme cases of online trolling and hate speech have even made headlines repeatedly over the past few years. While there is a growing body of research on impoliteness online (e.g. Hardaker 2013, 2017; Kienpointner 2018), the pragmatics of social media, and impoliteness, in particular, is still a nascent field of research (Hoffmann 2017; Xie and Yus 2018); furthermore, most of the existing literature has predominantly focused on Western languages, such as English and Spanish. For example, Bou-Franch and Garcés-Conejos Blitvich (2014) examined the sequential unfolding of a massive polylogal (multiparty) conflict in the comments for a YouTube public service 
announcement on teen homosexuality posted by a Spanish LGBT association. Their analysis problematised the assumption that a conflict consists of a beginning, middle, and end. They argued that conflicts in YouTube polylogues, characterised by multiparty participation and social media anonymity, are often unresolved and may never end, with a continuous discursive struggle of the middle. Their work is indicative of many of the approaches to impoliteness and social media in Western languages.

Chinese impoliteness online has been particularly underexplored. Researchers have just begun to explore it in contexts such as microblogging (Xie 2015; Zhang and Xie 2015) and forums (Kádár, Haugh and Chang 2013; Wang and Taylor 2019). Wang and Taylor (2019), for example, have uncovered similarities in the pragmatic processes across two languages/cultures - more specifically, the shared developments in the conventionalisation of polite forms for impolite functions in Chinese and British online forums within the last decade or so. Their analysis showed how certain lexical items became pragmaticalised within specific contexts while remaining unaffected in others. It also showed both diachronic and synchronic variations in the degree of conventionalisaton of the mock politeness people expressed. For example, the mock-polite usage was much more frequently observed in the area of the forums called 'Am I being unreasonable?' (AIBU), which elicits judgments and attitudes, than in other areas of the forums. The mock-polite usage seemed to be more expected in AIBU than elsewhere in the forums, which also helped explain how internet users were oriented towards the conventionalised meaning of implicational impoliteness even when it was still used with relatively low frequency compared to polite usage (i.e. low frequency but high saliency).

As an emerging commenting system for an increasing number of Chinese video-sharing sites, danmu has attracted attention from scholars in disciplines ranging from computer science (e.g. Chen, Gao, Rau and Chen 2015) to media and communication (e.g. Liu, Suh and Wagner 2016; Xie, He and Feng 2014); and a vast body of literature discussing danmu has mentioned in passing the widespread impoliteness phenomena on social media platforms (Feng 2018; Zhang 2015). However, danmu has rarely been investigated from the angle of linguistic im/politeness. Linguists (e.g. Li 2018a, 2018b; Zhang and Cassany 2019a, 2019b) have just started to explore danmu, but they have focused on topics other than im/politeness. For example, Zhang and Cassany (2019a) studied the danmu comments on a Spanish TV series, The Ministry of Time, which were collected from a fandom platform, and analysed the 
topics that attracted most interest from Chinese fans, such as interculturality and learning the Spanish language.

There are two existing studies focusing on linguistic impoliteness in danmu by Li (2018a, 2018b). In the first study, $\mathrm{Li}$ (2018a) cited a few examples from the danmu on popular Chinese interactive live shows on Douyu.com (斗鱼网红直播) and video clips of the TV programme Roast (吐槽大会) on Bilibili and loosely linked them to Leech's (2014) broad maxims of politeness, such as breaching the maxim of agreement. She did not analyse the impolite language use in detail. In the second study, Li (2018b) compared a sample of 500 online comments extracted from Douban (a Chinese website that features user reviews and recommendations for books, music and movies) and 500 danmu comments from Bilibili on the film So Young 2. She concluded that danmu comments tended to be shorter, and her survey participants, who were undergraduate students, felt that impolite danmu comments seemed to be more acceptable than impolite Douban comments. Once again, she did not look into the working mechanisms of impoliteness. Li's work represents a first step in studying linguistic impoliteness in danmu, but it focuses on attitudes towards rather than actual language use.

With respect to impoliteness strategies, which are one focus of the present study, meso- and micro-level analyses are needed to better understand the working mechanisms of impoliteness. In this study, existing typologies of impoliteness strategies (Bousfield 2008; Culpeper 1996, 2011, 2016) were adopted and modified for analysis; these typologies were selected because they were derived from meso- and micro-level analyses of a wide range of naturally occurring impoliteness data. Bousfield (2008) took his interactional data from several British fly-on-the-wall documentary serials, such as the BBC's The Clampers. He adapted Culpeper's (1996) impoliteness strategies by, for example, adding the 'challenge' linguistic impoliteness strategy, which is defined as asking the hearer $(h)$ "a challenging question, critically questioning the $h$ 's position, stance, beliefs... previous actions, etc" (Bousfield, 2008: 240). Drawing on an analysis of various data, including self-reports and the Oxford English Corpus, Culpeper (2016) identified twelve impoliteness strategies covering both conventionalised formulae (including insults, pointed criticisms/complaints, unpalatable questions and/or presuppositions, condescensions, message enforcers, dismissals, silencers, threats and negative expressives), and implicational impoliteness. Culpeper $(2011,2016)$ further identified three sub-types of implicational impoliteness. 
1. Form-driven: the surface form or semantic content of a behaviour is marked.

2. Convention-driven:

a. Internal: the context projected by part of a behaviour mismatches that which is projected by another part; or

b. External: the context projected by a behaviour mismatches the context of use.

3. Context-driven:

a. Unmarked behaviour: an unmarked (with respect to surface form or semantic content) and unconventionalised behaviour mismatches the context; or

b. Absence of behaviour: the absence of a behaviour mismatches the context.

(Culpeper 2011: 155-156)

The identified impoliteness strategies above, comprised of both overt and covert strategies, formed a good starting point for the present study. It is worth noting that as Culpeper (2016) and Bousfield (2008) pointed out, these typologies are not fixed categories: study participants were encouraged to adopt and adapt these categories and add new ones if they felt they could be improved. More details regarding adapting these categories to the analysis of danmu will be described in the methods section.

\section{Uses and gratifications theory and danmu}

Uses and gratifications theory has been one of the most influential theories in the field of communication. Why people use specific media and what specific needs they use them forfor example, to enhance knowledge, relax, seek companionship or escape from 'the real world'-form the driving questions behind this theory. Moving from a mechanical to a psychological perspective, uses and gratifications theory "has always provided a cutting-edge theoretical approach in the initial stages" of each new communications medium: "newspapers, radio, television and now the internet" (Ruggiero 2000: 27). Recently, with the rise of social media, the theory has been applied to social networking sites such as Facebook (Quan-Haase and Young 2010), Twitter (Chen 2011), YouTube (Khan 2017) and WeChat and Weibo (Gan and Wang 2015). It has been found that social media tends to be used for 
purposes other than consuming content and information (Hoffmann 2017). Eight common reasons or needs emerged from the literature: social interaction, information seeking, information sharing, passing time, entertainment, relaxation, communicatory utility, and convenience utility. For example, Whiting and Williams (2013) employed the gratification theory to explain why people use social media. Drawing on in-depth interviews with 25 social media users, they identified two additional uses and gratifications: expression of opinion, and surveillance of or knowledge about others.

Dапти is a relatively new medium of communication that has gained enormous popularity in China over the past few years, and scholars have just begun to employ uses and gratifications theory to analyse why people use danmu (Luo 2016; Qi and Hu 2017). Luo (2016) touched upon the themes of information sharing, such as internet slang, social interaction, entertainment and self-fulfilment. Furthermore, according to Luo (2016), prolific danmu users can satisfy their needs for self-fulfilment, as they are encouraged and rewarded by the main danmu site, Bilibili, to create new video content. Similar findings have been reported in Qi and Hu's (2017) study. In terms of language use, although it has been widely recognised that linguistic impoliteness prevails in danmu (Li 2018a, 2018b; Luo 2016), it has not been investigated from the perspective of uses and gratifications theory. Given the insights the theory can offer into emerging communication media, in the present study, it has been applied to analyse impoliteness in danmu. The research questions of this study are outlined as follows:

1. How do people express impoliteness in danmu?

2. Why do people express impoliteness in danmu?

\section{Methodology}

The data were taken from major Chinese video-sharing websites featuring the danmu function, including Bilibili, AcFun, and iQiyi. The danmu video corpora were constructed using a wide range of search terms ${ }^{1}$ relating to im/politeness (Wang and Taylor 2019) to

\footnotetext{
${ }^{1}$ The Chinese search terms of im/politeness are 礼貌 (polite), 有礼貌 (have politeness), 不礼貌 (impolite), 没 (有)礼貌 (not have politeness), 有礼 (have manners), 无礼 (have no manners), 讲理 (reasonable and rational), 不讲理 (unreasonable and irrational), 文明 (civil), 不文明 (uncivil), (有)素质 (have good manners/upbringing), 没素质(have no breeding), (有)风度 (have manners), 没(有)风度 (have no manners), 差辱 (abuse), 侮辱
} 
identify videos. In order to narrow the focus to more active danmu videos, only those that had more than 300 danmu comments were compiled into the corpora. It should be noted that the danти corpora had been collected as part of a larger corpus-assisted study of what constitutes $\mathrm{im} /$ politeness for Chinese-speaking internet users.

The videos identified were examined manually, and only those containing im/polite, metapragmatic comments and discussions such as “这人真没素质” [This person really has no breeding] were saved to the corpus, thus yielding 49 videos with a total of 26875 danmu comments, ranging from 304 to 1500 danmu comments per video.

Next, eight Chinese postgraduate students studying in the United Kingdom who were frequent danти users and viewers were invited to participate in the examination of the danmu data. They were instructed in the impoliteness strategies and frameworks (e.g. Culpeper 1996, 2011, 2016; Bousfield 2008) that were reviewed earlier in this paper. The participants (designated by ' $\mathrm{P}$ ' followed by a number, e.g. P1) were asked to individually examine two videos with danmu on them; one was a web TV monologue (Video A) and the other was a dyadic interaction in the Q\&A session of a TV interview (Video B). They were then asked to identify impolite utterances from a viewer's perspective and categorise them by adopting and modifying the existing typologies of impoliteness strategies identified by Culpeper (1996, 2011, 2016) and Bousfield (2008): conventionalised impoliteness (challenges, insults, pointed criticisms/complaints, unpalatable questions and/or presuppositions, condescensions, message enforcers, dismissals, silencers, threats and negative expressives) and the implicational impoliteness of convention-driven (internal mismatch and external mismatch), form-driven and context-driven strategies. In an additional category called 'other', the study participants were asked to specify categories that emerged from the data but were not covered in the existing list.

(abuse), 辱骂 (verbal abuse), 喷 (abuse), 黑 (abuse), 骂 (abuse), (人身)攻击 (abuse), 粗鲁 (rude), 鲁莽 (rude), 粗暴 (rude and savage), 粗俗 (unrefined), 唐突 (offend), 冒犯 (offend), 冒昧 (offensive), 冒失 (offensive and rash), 莽撞 (offensive and rash), 得罪 (offend), 触怒 (offend), 触犯 (offend), 野蛮 (rude and barbarian), 蛮横 (rude and unreasonable), 嘲讽/冷嘲热讽 (mock/mocking/sarcastic), 嘲弄 (mock/mocking), 嘲笑 (mock), 取笑 (mock), 讽刺 (mock/sarcasm/sarcastic), 暗讽 (insinuate with sarcasm), 奚落 (mock/sarcasm/sarcastic), and 挖 苦 (mock/sarcasm/sarcastic). Developed from the literature and dictionaries, these search terms potentially signal discussion of im/politeness. Akin to the British data, the Chinese corpora were compiled through an iterative process until a point of saturation was reached. Please see Wang and Taylor (2019) for more details. 
After individual coding, the participants gathered as a focus group to discuss their categorisations, and a group consensus was reached. Overall, the group identified a total of 125 impolite utterances - 46 impolite utterances in Video A and 79 in Video B — falling into various categories. Then, the focus group moved on to the second part of discussions regarding why people are impolite in danтu. The discussions were transcribed and analysed thematically to understand the participants' perceptions and interpretations.

After this step, four participants applied the agreed-upon coding scheme to further examine 20 videos in the video corpora - five videos each, based on their indicated preferences. They were once again asked to identify impolite utterances from the danmu comments and to categorise the impoliteness strategies employed in the utterances while making brief notes about why they thought an utterance was impolite and why they classified it that way. If an utterance used more than one impoliteness strategy, the categorisation focused on the primary strategy, but this rarely occurred in the data because danти comments are usually very short. After a round of individual coding, the participants worked in two pairs to cross-check each other's coding. If a disagreement arose, they would discuss it and reach a consensus, making a note next to the coding. Through these rounds of coding, along with the focus group discussions, 1564 impolite comments using a range of impoliteness strategies were identified. Section 5 of this paper reports on how people expressed impoliteness in danmu, basing the analysis on what the participants had identified as impolite. Section 6, based on the focus group interview data, discusses why people are impolite in danmu.

\section{How do people express impoliteness in danmu?}

Overall, there were 1564 impolite utterances employing a variety of impoliteness strategies in 22 danmu videos in total. By adopting and modifying Culpeper's $(1996,2011,2016)$ and Bousfield's (2008) typologies of impoliteness strategies reviewed earlier, the participants identified seven impoliteness strategies employed in the danmu data. Among these, there were five categories of conventionalised impoliteness formulae-insults, negative expressives, threats, challenges and pointed criticisms - and two types of implicational impoliteness - convention-driven and form-driven impoliteness strategies - as outlined in Figure 2. 


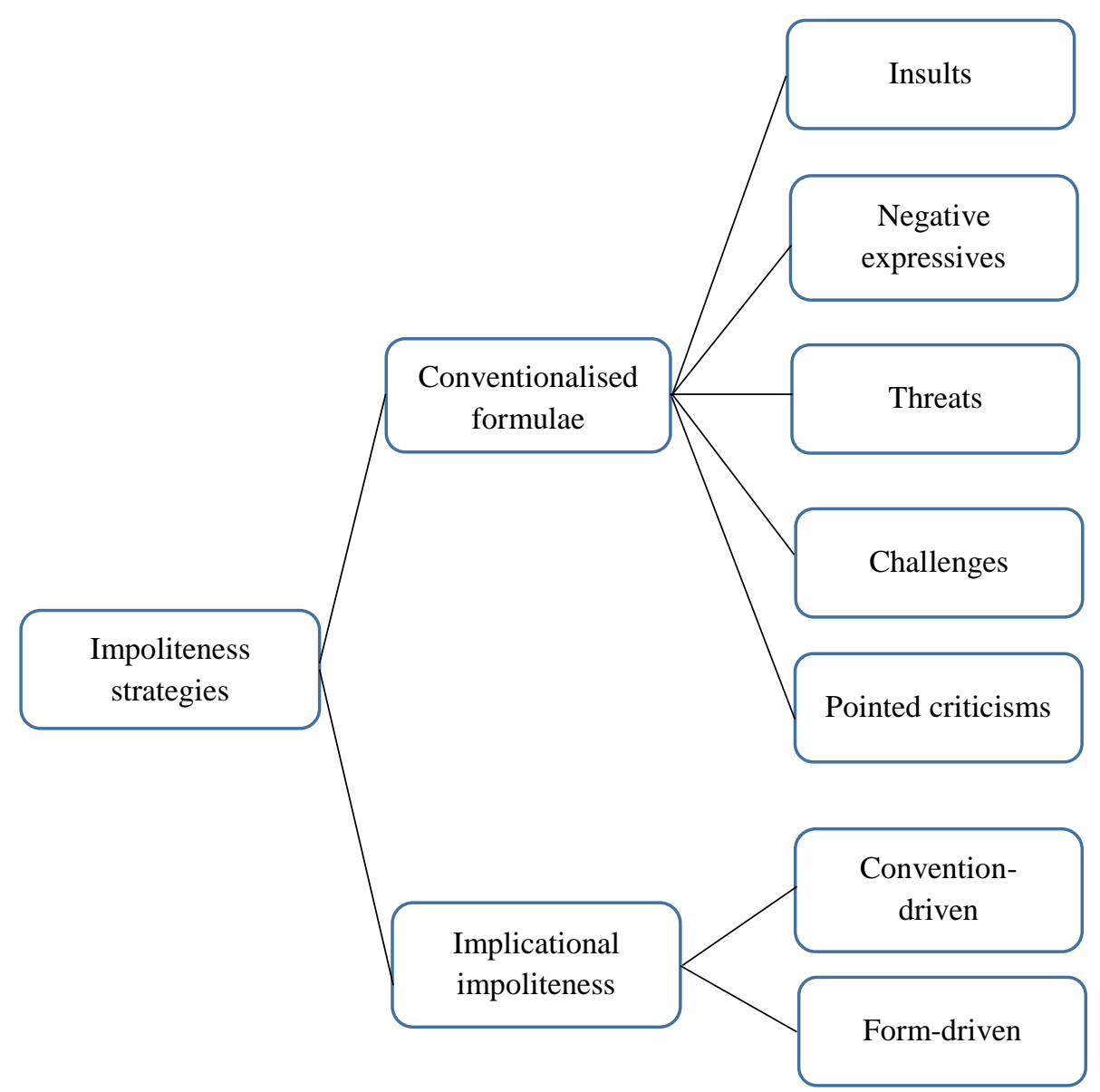

Figure 2. A model of impoliteness strategies in danmu

The raw frequency and distribution of each identified impoliteness strategy in the impolite danти comments is presented in Figure 3. 


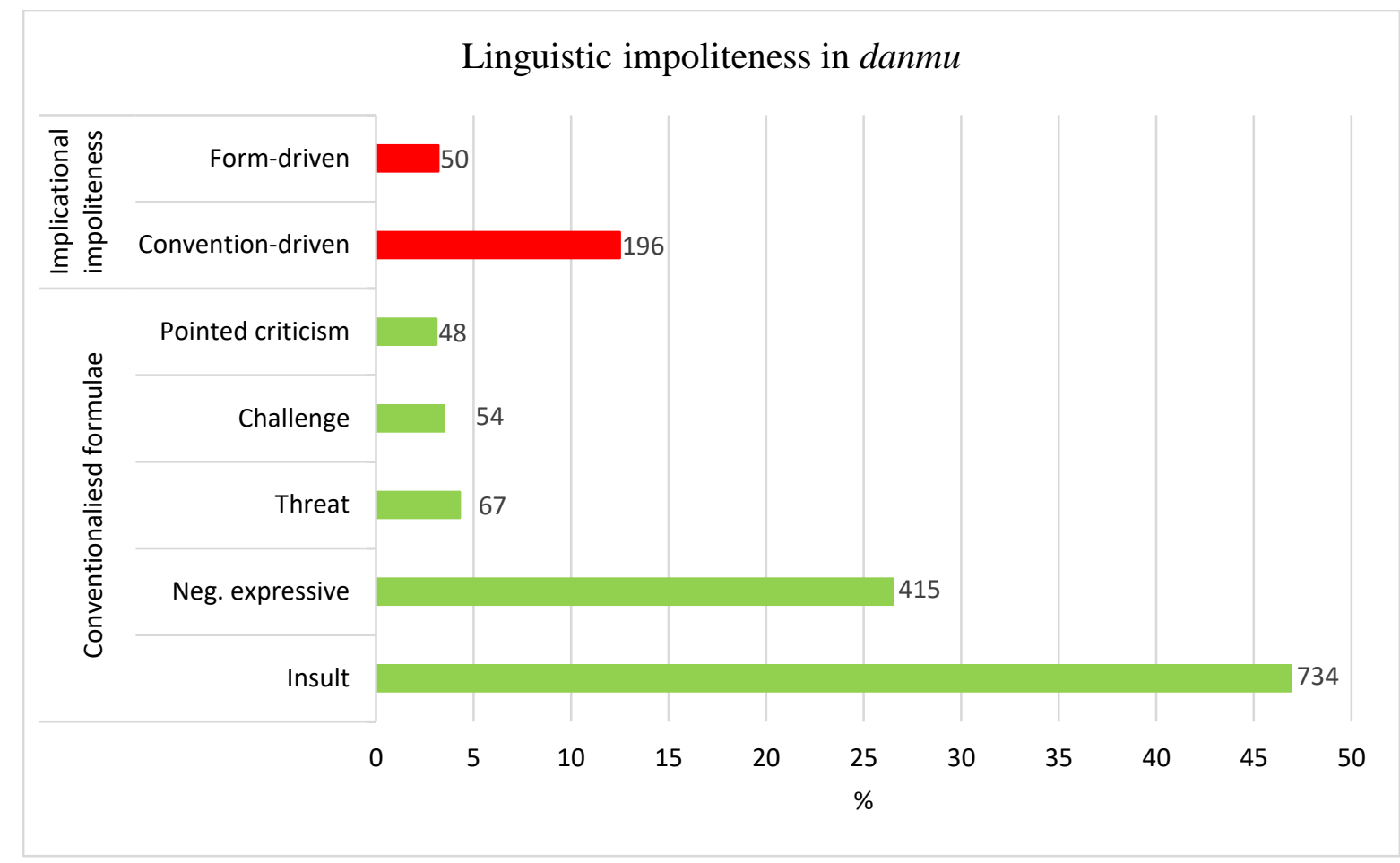

Figure 3. Types of impoliteness strategies (the $x$-axis indicates the percentages of the category with respect to the total 1564 items that were identified as impolite utterances; the numbers at the end of each bar indicate the raw frequency of the category)

As can be seen from Figure 3, overt impoliteness strategies were used more frequently than covert strategies. Taken together, conventionalised impoliteness formulae (including insults, negative expressives, threats, challenges and pointed criticisms) accounted for $84.3 \%$ of the total 1564 impolite utterances in danmu; and implicational impoliteness, including convention-driven and form-driven implicational impoliteness, accounted for $15.7 \%$ of the total. The identified impoliteness strategies are reported in the sections below in sequence.

\subsection{Conventionalised impoliteness formulae}

Conventionalisation is "inherently evaluative: when we learn, through socialization in a community or group, that 'this is the way to do some thing' ... what we are implicitly learning is that this is the right way of doing this thing ... in this type of context" (Terkourafi 2015: 16). The participants, who were experienced danтu users, considered an expression to be conventionalised for impolite use in danmu contexts if, in their experience, the expression is frequently used in danmu contexts to achieve impoliteness. Five categories of 
conventionalised formulae were identified in the data: insults, negative expressives, threats, challenges and pointed criticisms.

\section{Insults}

The most common type of conventionalised impoliteness formulae was insults, referring to personalised negative assertions and references (Culpeper 2011, 2016), and accounting for 734 impolite utterances (46.9\%). The insults identified could be directed at various targets, including the video maker and other commenters, such as in examples (1) and (2).

(1) 你们强调 摄像头的是魔鬼 吗 ${ }^{2}$

2PL stress camera NOM COP demon Q

'You guys who stressed the camera are horrible people'

The attack in (1) was directed at other commenters. In the video, at a certain point, the host of the web TV monologue seemed to be looking at the incorrect camera, provoking danmu comments telling him where the camera was, and in doing so, questioning his professional ability as a host (noted by P1, P5, and P7). The commenter in (1) consequently launched a personalised insult at the previous commenters, displaying the interactivity of danmu comments. The participants regarded the utterance in (1) “你们强调摄像头的是魔鬼吗” [Are you the guys who stressed the camera demons] as a counter-impolite move to the other commenters who mentioned the camera.

In addition to insults targeting other commenters and the video maker, insults were often found to target other people who appeared in the video, as in (2).

(2) 这 女 的咋这么 恶心

this female NOM why so disgusting

'How come this woman is so disgusting'

这 女 的 好 烦

this female NOM very annoying

'This woman is very annoying'

\footnotetext{
${ }^{2}$ All the data excerpts are original. In presenting the excerpts, both a literal translation and a free translation (in single quotation marks) are given. The glosses follow the general guidelines of the Leipzig Glossing Rules.
} 
In this example (taken from Video B), in which the host invited the audience to ask the interviewee - a famous author - questions, the two insults targeted a female audience member, attacking her for raising silly, yet harsh, questions. In fact, during the female audience's conversation with the author, more insults followed the two cited examples. All the focus group participants stated that a flow, or an outburst, of impolite comments such as these are frequently observed in danти because, as P3 explained, for most danmu viewers, “the very fun of danmu lies in the inter-resonance of the comments" ( 弹幕的乐趣就在于引 起共鸣) and more often than not, viewers resonate with the impolite comments. The participants revealed that, as they are danmu viewers, most of the time they do not feel such insults are inappropriate because they believe that the target of the insults has usually done something wrong in the first place (in this case, the female audience member seems to intentionally ask hostile questions to make the author's life difficult). They also emphasised that danmu creates a public space for sharing oppositional messages, the messages resonate with each other, and the viewers resonate with the messages and may perceive them as less offensive. This is comparable to the findings of Lange's (2014) study of YouTube rant videos: while scholars often perceive rants as impolite, rant video commenters may not perceive them as inappropriate.

\section{Negative expressives}

The second most common impoliteness strategies in danmu were negative expressives, such as curses and ill wishes (Culpeper 2011, 2016), which accounted for 415 of the impolite utterances and $26.5 \%$ of the data. The identified formulae were dominated by swear words, such as in (3), (4) and (5).

(3) 卧 槽

lie groove

'Fuck'

(4) 草泥马

grass mud horse

'Fuck you'

(5) TMD

TMD

'Fuck' 
As common curse words tend to be censored online, Chinese netizens have coined homophones, such as (4) 草泥马 (cao ni ma, literally meaning 'grass, mud and horse'), which denotes 操你妈 (cao ni ma, literally meaning 'fuck your mother') or used the pinyin acronyms of the swear words, such as in (5), where “TMD” refers to 他妈的 (ta ma de), to avoid censorship. TMD are the initial letters of ta ma de, which is equivalent to 'fuck', and it literally translates as 'his mother's'. There were also ill wishes in the data, such as (6) below.

(6) 这样的老板 活该 倒闭

this kind of DET boss deserve go bankrupt

'Companies with bosses like this deserve to go bankrupt'

\section{Threats}

Threats (Culpeper 2011, 2016) were the third most frequently used category of conventionalised impoliteness formulae in the data. There were 67 threats $(4.3 \%$ of all the impolite comments), as (7) and (8) illustrate.

(7) 你 再 说 - 遍 试试

2SG again say one CLF try try.

'You can try to say that again'

(7) is a commonly used formulaic expression that is a generic threat in spoken Chinese, whereas (8) below is more specific to danmu.

(8) 贴吧 见

Tieba see

'See you in Tieba'

All the focus group participants identified “贴吧见” [see you in Tieba] as a conventionalised threat in a danmu conflict. Tieba refers to Baidu Tieba, the largest Chinese forum, which provides more room for extended argument than the limited space enabled by danmu comments. 


\section{Challenges}

The fourth most frequently used category of conventionalised formulae was challenges. Bousfield described the 'challenge' linguistic impoliteness strategy as the following: "ask $h$ a challenging question, critically question $h$ 's position, stance, beliefs, assumed power, rights, obligations, ethics, previous actions, etc" (2008: 240). As the participants noted, in the danmu context, the hearer ( $h$ ) may not always be the target of the challenges, such as in example (9) below. Therefore, in this study, this strategy was reformulated by replacing 'the $h$ ' with 'the target'. There were 54 occurrences of challenges in the data, accounting for nearly $3.5 \%$ of the total impolite comments. This category of comments often challenges the views expressed in the video. For example, (9) was taken from Video A, in which the host argued that replying to a manager in a WeChat work group impacted the employee's work efficiency because an employee should not be interrupted.

(9) Host: 一个 员工 在 回复你的同时 one CLF employee while reply 2SG DET meantime 'When an employee replies to you'

人家还在干别的活 that person still while do other DET work

'She/he is still doing other things'

手中的活不能被打断

hand in DET work can't PAS interrupt

'The things they are handling cannot be interrupted'

Commenter: 这 就 有点疑问了, 不能被打断?

this then have bit question AUX, can't PAS interrupt

'This then is a bit questionable, can't be interrupted?'

The commenter in (9) above rhetorically challenged the host's stance, questioning his argument by asking a challenging question, why '(the employee) can't be interrupted'. As the 
participants noted, the commenter did not genuinely expect an answer from the host or other commenters.

\section{Pointed criticisms}

The fifth category of conventionalised formulae was pointed criticisms (Culpeper 2011, 2016), which means expressing criticism in a direct and unambiguous way. Forty-eight occurrences of this type were identified, accounting for $3.1 \%$ of the danmu data.

Interestingly, in danmu, this type of impolite comment could target either the hearer, including the video maker, as in (10), or a third-party non-hearer (e.g. a subject being discussed in the video), ranging from a person to an event, such as in (11).

$\begin{aligned} & \text { (10) 误 人 子弟 } \\ & \text { hamper } \text { people young people. }\end{aligned}$

'Extremely misleading'

The commenter above directly and harshly criticised the video maker for being completely wrong and making an extremely misleading video. In addition to criticisms directed at the video maker, or the hearer, danmu criticisms often go beyond that, and are directed at nonhearers.

(11) 摆谱， 真正的 大人物... 站 在那里，别人 就 会 给 他 尊敬 put on airs, real DET big figure... stand at there, others then will give him respect 'Put on airs! A genuinely big figure will be respected by others without putting on airs'

Example (11) was taken from the same video as example (9) (Video A). When the comment above flew out, the host was criticising the manager, who fired an employee for replying "OK" to him in their work WeChat group. The commenter agreed with the host, and also criticised the manager for putting on airs. All the focus group participants perceived (11) as an impolite comment, yet still appropriate from a dапmu viewer's perspective. Even though the target of the pointed criticism was not actually the hearer, and the target may never hear the attack, this is a frequently used type of criticism in danmu. It seems possible that people 
use or watch impoliteness behaviours in danmu comments in part to connect with other people by building and reinforcing in-group alliances (P1, P3, P4, P6, P7). This once again echoes the point observed earlier in relation to insults; that is, impolite utterances can actually play an important role for the performers of impoliteness and the observers, to find connection with other danmu users/viewers.

\subsection{Implicational impoliteness}

In addition to the five categories of conventionalised impoliteness strategies identified above, which accounted for $84.3 \%$ of the impolite utterances, there were 246 occurrences of implicational impoliteness, amounting to $15.7 \%$ of the total 1564 items. Two types of implicational impoliteness strategies emerged from the data: (1) convention-driven implicational impoliteness, including both (1a) internal mismatch, where the context projected by part of an utterance mismatches that which is projected by another part, and (1b) external mismatch, where the context projected by an utterance mismatches the context of use, and (2) form-driven implicational impoliteness, where the surface form of linguistic behaviour is marked (Culpeper 2011, 2016), and these mismatches trigger impolite inferences.

\section{Convention-driven impoliteness strategies}

Convention-driven implicational impoliteness strategies were the third most frequently used category of impoliteness strategy overall in the danmu data, accounting for nearly $12.5 \%$ of the total. There were 196 occurrences of convention-driven implicational impoliteness, consisting of 56 internal mismatches and 140 external mismatches.

Internal mismatches. The context projected by part of an utterance does not match that which is projected by another part, such as in (12) and (13).

$$
\begin{aligned}
& \text { （12）毫无 违和感啊（滑稽） } \\
& \text { none sense of disharmony FP (ridiculous) } \\
& \text { 'There is no sense of disharmony (ridiculous)' }
\end{aligned}
$$


Example (12) is a comment on an excerpt taken from a badly made TV drama in which the hero's scenes of traveling overseas were all edited in Photoshop. The editing was so poor that the background and the character did not match. The first part of the utterance “毫无违和感 啊” [There is no sense of disharmony] was a seemingly polite comment to suggest that all the things in “the scenes in TV drama are harmonious” [电视制作画面和谐] (P1). The negative evaluation in parentheses “(滑稽)” [ridiculous] “marks a sudden turn” [话锋一转] (P1), led to an internal mismatch that gave rise to an impoliteness interpretation of the overall message. The commenter was actually attacking the poor production quality of the scenes, and the positive comment in the first part was sarcastic.

\section{(13) 您 真 TM 有 礼貌 \\ 2SG (polite form) really $\mathrm{TM}$ have politeness \\ 'You (polite form) are really fucking polite'}

Example (13) is a sarcastic comment about a contestant who was arguing with the TV show's host in the video. The participants classified (13) as an internal mismatch that constitutes an example of mock politeness in which politeness strategies that are obviously insincere are performed and remain surface realisations (Bousfield 2008). While “您真...... 有礼貌” [You (polite form) are really polite] is a seemingly polite comment in which the polite form of address for you (nin) is employed, it clearly clashes with the taboo word "TM" [fucking], resulting in the opposite implication: the entire message being reinterpreted as impolite (i.e. “选手真没礼貌” [the contestant was really impolite]) (P1). These kinds of internal mismatches - that were found to be a conventionalised impoliteness strategy in the Chinese forum data (Wang and Taylor 2019)—were also commonly employed in the danmu comments.

External mismatches. Compared with internal mismatches (56 instances), external mismatches (140 instances), where the context projected by linguistic behaviour mismatches the context of use, were more frequently observed in the data, as (14), (15), (16) and (17) illustrate.

(14) Context: The actress's portrayal of falling off the cliff is so bad that numerous danmu comments mock her bad acting. 


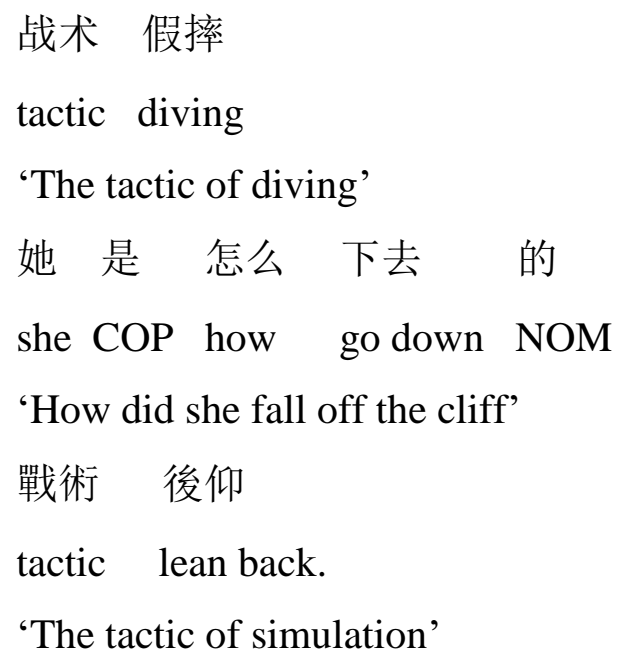

The participants identified the first and the third comment above as context-driven implicational impoliteness because they refer to diving, a term used in football settings when a player attempts to gain an unfair advantage by falling to the ground and feigning an injury. Clearly, the context projected by the danmu comments are “足球评论” [football commentary], which clashed with the context of use, “TV drama acting commentary” [电视 剧演技评价], but implied a “very harsh criticism” [挺尖锐的批评] that “mocks the actress X's acting, which is so bad she's like a bad football player that takes dives” [讽刺这名 X 演 员演技太差了, 就跟假摔的球员一样] (P5).

(15) Context: In the video, the host of the web TV monologue does not look at the correct camera for 19 seconds, giving rise to a series of danmu comments that tell him where the camera is.

摄像头在这呢

camera at here FP

'The camera is here'

喂! 摄像头 在 这 边

hello! camera at this side

'Hello! The camera is here'

摄像头

camera

'Camera' 
All the participants identified the comments above as impolite and categorised them as external mismatches under the category of convention-driven implicational impoliteness. These comments pointing out where the camera was do not appear to be impolite on the surface. However, by telling the host where the camera was, the commenters questioned his professional ability as a host (P1, P5, P7). Several participants (P1, P2, P4) highlighted the fact that the first impolite comment, “摄像头在这呢” [The camera is here ne], rather than flying by the screen which is the default setting, was placed in a fixed position on the top middle area of the screen for 0.04 seconds. That position aligns with the position of the camera. The participants perceived the fixed comment as more impolite than comments that simply flew by, even though the three comments have similar wording, because the positioning of the first comment was marked: “就跟教小孩似的，指着这儿告诉他镜头在 这” [just like teaching a child, pointing here, telling him the camera is here] (P2).

(16) MDZZ

MDZZ

'Fucking idiot'

这么睿智

so wise

'So wise and smart'

智障 吧

idiot FP

'Idiot'

In (16), the participants classified the second comment, “这么睿智” [so smart], as an external mismatch under the category of convention-driven implicational impoliteness, and, according to the participants, there was a strong hint of sarcasm in the comment. As P3 noted, this seemingly polite comment appeared to praise the guest on the TV show for being wise and smart - and, clearly, it clashed with the series of negative expressives surrounding it that attack the guest for being an idiot — thus leading to it being interpreted as impolite and constituting an example of sarcasm/mock politeness.

(17) Context: The host is discussing how an employee should reply to his/her boss in a work WeChat group if a minimal response such as " $\mathrm{OK}$ " is considered impolite 
and inappropriate. A series of danmu comments, which are conventionalised replies to the emperor in old Chinese imperial settings, including the following, fly by.

臣, 遵旨 $\odot \nabla \odot$

subject, obey the emperor's decree

'I'm at Your Majesty's command $\odot \nabla \odot$ '

以后就回臣遵旨

in future then reply subject obey the emperor's decree

'Will reply I'm at Your Majesty's command'

该回复 遵旨

should reply obey the emperor's decree

'Should reply at Your Majesty's command'

皇上 圣明

emperor sacred bright.

'Your Majesty is intelligent and capable'

All the participants identified the above comments as context-driven implicational impoliteness because the context they projected was replying to an emperor in an ancient Chinese imperial court, whereas the context of use was a modern corporate setting; the two contexts clearly clash, leading to an impoliteness inference. In other words, these comments were insincere and heavily sarcastic in that they implied that the boss should be treated as if he were the emperor and the employee should be as much flattery as possible (P1, P3, P4, P5, P6, P8). According to P5 and P7, such sarcastic comments are common in danmu, and they make watching videos more interactive and entertaining. All the comments in (17), including the last line, are convention-driven impoliteness, which was the third most commonly used subcategory of impoliteness strategies in the data.

\section{Form-driven impoliteness strategies}

In addition to convention-driven impoliteness, the other type of implicational impoliteness strategy found in the danmu data was form-driven impoliteness. There were 50 identified occurrences, amounting to $3.2 \%$ of the total. The surface form of an utterance is marked and triggers an impolite inference (Culpeper 2016), as (18) shows below. 
(18) Context: The video maker begins by saying “列位” (lie wei) [gehwa] to greet the viewers. “列位 lie wei” is an address term used to refer to everyone in old Chinese, but it is rarely used in modern Chinese. After his greeting, comments of echoic irony, such as the two listed below, fly by the screen.

裂胃

crack stomach

'Lie wei'

裂胃哥

crack stomach bro

'Lie wei bro'

Both comments in (18) contain a sarcastic mimicry of lie wei by using homophonic characters “裂胃” with the same pronunciation that do not make any sense in Chinese. The surface form of the utterances, “裂胃” (literally meaning crack stomach), is marked because the form is meaningless, and viewers "cannot understand them at all if they do not watch the video" [不看视频根本就不能理解这些话是什么意思] (P2). All the participants perceived the utterances in (18) as form-driven implicational impoliteness that mock the video maker for using a strange word that could hardly be understood. The participants revealed that the addition of “哥” [bro, literally meaning older brother] to lie wei in the second utterance intensifies the sarcasm because “哥” [brother] in a non-kinship context is a term of address in spoken Chinese that usually refers to someone who is more senior and/or more experienced in an affectionate or sarcastic way (P1, P2, P5, P7).

In short, impolite utterances are indeed not uncommon in danmu. In the data, there were 1564 identified impolite comments in total. They mainly employed five categories of conventionalised impoliteness formulae - insults, negative expressives, threats, challenges and pointed criticisms - and two categories of implicational impoliteness strategies - formdriven and convention-driven strategies. The focus of this paper can now shift to why people are impolite in danmu. 


\section{Why are people impolite in danmu?}

By applying uses and gratifications theory to analyse the discussions on why people are impolite in danmu in the focus group interviews, five uses and gratifications were identified: social interaction, entertainment, relaxation, expression of (usually differing) opinions, and finding connection. The last two uses and gratifications for performing impoliteness in danmu were new categories that emerged from the data.

\section{Social interaction}

The participants suggested that commenters are impolite in danmu for social interaction, in that danmu users can “和关注共同话题的人实时交流观点, 进行互动” [exchange views and interact with people who follow the same topics in real time] no matter where they are, whether they agree with the video and/or each other or not; in that context, making impolite comments in danmu can make online video watching "a more critical...yet more engaging co-viewing experience in which people can socialise while watching a video at the same time" [批判性更强......但互动性更强, 大家一起观看视频的同时还可以 social]. Focus group participants highlighted the unique interactivity of danmu videos. In traditional video commentary systems such as YouTube's, reading and responding to comments is separate from watching the videos, but danmu videos differ by allowing and "encouraging viewers to integrate interaction into their watching experience" [鼓励大家把互动融入到观影体验中], which makes it easier to create resonance on social media platforms.

\section{Entertainment}

The study participants also reported being impolite in danmu for entertainment purposes. They mentioned that making a good sarcastic comment can make others laugh, "entertaining both themselves and others” [娱乐自己, 也娱乐他人] and creating humour and comic relief for themselves and other viewers. More often than not, one sarcastic comment brings out another sarcastic comment, leading to an accumulation of entertaining effects. The participants felt that people usually made impolite comments in danmu for fun. 


\section{Relaxation}

The participants also mentioned performing impoliteness in danmu for relaxation. Some explained that because danmu comments are anonymous and online, they felt “不受限制” [free from constraints] and that they “可以不计后果” [can be free from consequences]. Some participants described how using language to attack someone unlikely to respond, which they could not do in real life, helped them to “relax the mood" [放松心情] and “escape from reality and stress” [逃避现实压力].

\section{Expression of (usually differing) opinions}

The participants reported using impoliteness in dапти to express their opposing opinions. Some of the comments were, "if there is a disagreement, (I) can express it immediately" [有 不同意见, 就立刻可以表达出来] and “It's OK to rant, criticise, mock and attack others in danmu” [弹幕里吐槽、批评、讽刺、抨击别人都是 $\mathrm{OK}$ 的] because it is a public “platform for emotional expression” [表达情感的平台] of different opinions which often resonate with each other, and sometimes it is even “a place to vent” [发泄情绪的地方].

\section{Finding connection}

Impoliteness usage in danmu as a means of finding connection was also mentioned.

Respondents discussed how they build bonds with those who share the same concerns by, for example, harshly criticising someone who is behaving inappropriately in the video, or by jointly challenging a viewpoint expressed in the video. Respondents mentioned that (18) (cited in Section 5.2) —in which several viewers made sarcastic comments, such as “臣遵旨” [I'm at Your Majesty's command] one after another to attack the boss in the video-is a typical example. The study participants stated that people can always form coalitions by making impolite comments in danmu that attack something perceived as wrong or someone who has done incorrect things, as the viewers do in (18), thus forming alliances. 


\section{Discussion}

Seven main impoliteness strategies emerged from the data on how people show impoliteness in danтu: there were five categories of conventionalised impoliteness formulae-insults, negative expressives, threats, challenges and pointed criticisms - and two types of implicational impoliteness - convention-driven and form-driven impoliteness. Proportionally, the top three most common impoliteness strategies employed in danmu comments were the conventionalised formulae of insults (734 occurrences, 46.9\%), negative expressives (415 occurrences, 26.5\%), and convention-driven implicational impoliteness (196 occurrences, $12.5 \%$ ), accounting for nearly $86 \%$ of the total, as illustrated in Table 1 .

Table 1. The impoliteness strategies employed in danmu

\begin{tabular}{|c|c|c|c|c|}
\hline & Subcategory & \multicolumn{2}{|c|}{ Occurrences } & $\%$ \\
\hline \multirow{6}{*}{$\begin{array}{l}\text { Conventionalised } \\
\text { impoliteness } \\
\text { formulae }\end{array}$} & Insults & \multicolumn{2}{|c|}{734} & 46.9 \\
\hline & Negative & \multirow{2}{*}{\multicolumn{2}{|c|}{415}} & 26.5 \\
\hline & expressives & & & \\
\hline & Threats & \multicolumn{2}{|c|}{67} & 4.3 \\
\hline & Challenges & \multicolumn{2}{|c|}{54} & 3.5 \\
\hline & $\begin{array}{l}\text { Pointed } \\
\text { criticisms }\end{array}$ & \multicolumn{2}{|c|}{48} & 3.1 \\
\hline \multirow{4}{*}{$\begin{array}{l}\text { Implicational } \\
\text { impoliteness }\end{array}$} & Convention- & \multicolumn{2}{|c|}{196} & \multirow[t]{2}{*}{12.5} \\
\hline & driven & $\begin{array}{c}\text { Internal } \\
\text { mismatches } \\
56\end{array}$ & $\begin{array}{c}\text { External } \\
\text { mismatches } \\
140\end{array}$ & \\
\hline & Form-driven & \multicolumn{2}{|c|}{50} & 3.2 \\
\hline & Total & \multicolumn{2}{|c|}{1564} & 100 \\
\hline
\end{tabular}

As shown in the table, convention-driven implicational impoliteness, and its subcategory of external mismatches illustrated by examples (14) to (17), was prominent in the data. It is worth noting that compared with the previously cited studies of impoliteness-such as those of face-to-face interaction in TV documentaries, including The Clampers (Bousfield 2008), military training and university students' self-reported events of impoliteness (Culpeper 
1996, 2011, 2016) — the danтu dataset seems to be richer in implicational impoliteness. Perhaps, as suggested by the study participants, watching videos while simultaneously reading overlaid comments tends to provide more multimodal resources that seem to make it easier for people to make an impolite inference, encouraging the use of implicational impoliteness. It is perhaps possible that the preponderance of implicational impoliteness is in some way related to language use in Chinese culture; however, there is currently be no evidence to back up this supposition so far in the current and existing studies, and the study participants did not mention it. It warrants further research.

With respect to why people perform impoliteness in danmu, five uses and gratifications were identified: social interaction, entertainment, relaxation, expression of (usually differing) opinions and finding connection. These findings are reminiscent of the identified uses and gratifications for using social media in general (Whiting and Williams 2013). However, there are differences. People often use linguistic impoliteness in danmu both to express a different view — such as challenging the mainstream, the video content, the video maker and/or other commenters - and to find connection with other danmu users/viewers; these two forms emerged as new categories of uses and gratifications for performing impoliteness in danmu. The findings suggest that danmu viewers and users do not necessarily perceive impolite utterances as inappropriate. For them, impolite comments often help reveal problems with the views expressed and/or subject matters being discussed in the videos, thus constructing an emotional public sphere for people to voice their different opinions that might resonate with others. Through expressing impoliteness together in co-viewing, danmu users can build bonds and find connection with other danтu users who share similar concerns. Indeed, using social media often contributes to the feeling of connectedness (Seargeant and Tagg 2014; Yus 2017). More specifically, the findings about impoliteness in danmu are reminiscent of Lange's (2014) study of YouTube rants that argued that rants — which scholars have generally regarded as impolite and inappropriate - are not viewed as inappropriate by commenters because, under the right circumstances, ranting helps construct an emotional public sphere that generates discussion among those YouTube participants who are similarly concerned about their online communicative rights and privileges.

In a similar vein, as danmu viewers, the participants in this study felt that most of the impolite danти comments were not inappropriate because the impolite utterances were resonant and/or oppositional messages to the video content, the video maker and/or other 
comments: these are expected for dапmи environments, echoing the identified usage of expressing a different view, as discussed earlier. The dialectic of resonance and opposition seemed to underpin all the impolite utterances in the danmu data. For example, as illustrated by (2) above, the second impolite comment attacking the person in the video frame echoed the first impolite comment, creating resonance in their oppositional messages. Danmu seems to create an emotional public space for sharing oppositional messages/discourses and finding connection, and dапти users and viewers usually do not regard such impolite comments as inappropriate. As Lange (2014) has insightfully noted, there seem to be discrepancies between scholars and social media users in evaluating the appropriateness of impolite utterances online. Such intriguing discrepancies can offer insights to advance the understanding and conceptualisation of impoliteness in social media.

Apart from linguistic expressions, which formed the focus of the present study, there are other multimodal resources in dапти that could be used to achieve impoliteness, such as using different colours and fonts for characters in danmu comments and the trajectories of how said comments 'fly' by on the screen. Multimodal discourse analyses of a wider range of visual data would be beneficial (See Zhang \& Cassany, this Volume). Further studies of impoliteness in danmu are warranted.

\section{Conclusion}

This study has explored how and why people are impolite in danmu. While it has been widely recognised that linguistic impoliteness prevails in danmu, the means and reasons for this have rarely been studied. This study has addressed this void. Based on an analysis of danmu comments identified by participants as impolite, seven impoliteness strategies were identified: five categories of conventionalised impoliteness formulae (insults, negative expressives, threats, challenges and pointed criticisms) and two types of implicational impoliteness (convention-driven and form-driven impoliteness). To understand why people are impolite in $d a n m u$, this study applied uses and gratifications theory to analyse the focus group interview data on how performing impoliteness in danmu could meet people's needs and bring them satisfaction. Five uses and gratifications were identified: social interaction, entertainment, relaxation, expression of (usually differing) opinions and finding connections. 
This research contributes to the existing literature in several ways. First, the paper breaks disciplinary boundaries by applying uses and gratifications theory, which has begun to gain prominence in social media research, outside the field of linguistics. Second, the analysis of the uses and gratifications for expressing impoliteness in danmu offers preliminary insight into this behaviour. Third, this research contributes to a better understanding of the means by which people show impoliteness in $d a n m u$, including implicational impoliteness, which has been largely unexplored in social media research. While internet pragmatics has begun to attract more attention from scholars, im/politeness in Chinese social media remains largely uncharted terrain in terms of research. More theoretical and empirical research in the vein of the present study is needed to advance our understanding of the vast, ever-expanding world of social media.

\section{References}

Alexa. 2019. bilibili.com: Competitive Analysis, Marketing Mix and Traffic. https://www.alexa.com/siteinfo/bilibili.com

Bou-Franch, Patricia, and Pilar Garcés-Conejos Blitvich. 2014. "Conflict management in massive polylogues: A case study from YouTube." Journal of Pragmatics 73: 19-36.

Chen, Gina Masullo. 2011."Tweet this: A uses and gratifications perspective on how active Twitter use gratifies a need to connect with others." Computers in Human Behavior 27(2): 755-762.

Chen Y., Q., Gao, and P.L. Patrick Rau. 2015. "Understanding Gratifications of Watching Danmaku Videos - Videos with Overlaid Comments." In Cross-Cultural Design Methods, Practice and Impact, ed. by P.L. Patrick Rau, 153-163. Cham: Springer.

Culpeper, Jonathan. 1996 "Towards an anatomy of impoliteness." Journal of pragmatics 25(3): 349-367. 
Culpeper, Jonathan. 2008. "Reflections on impoliteness, relational work and power." Impoliteness in Language: Studies on Its Interplay with Power in Theory and Practice 21, eds. by Bousfield, Derek, and Miriam A. Locher, 17-44. Berlin: Mouton de Gruyter.

Culpeper, Jonathan. 2011. Impoliteness: Using Language to Cause Offence. Cambridge: Cambridge University Press.

Culpeper, Jonathan. 2016. "Impoliteness strategies." In Interdisciplinary Studies in Pragmatics, Culture and Society, eds. by A. Capone and J.L. Mey, 421-445. Cham: Springer.

Feng, Shaodan 冯韶丹. 2018. "danmu shipin yuyan de sida tezheng" 弹幕视频语言的四大 特征 [Four main features of danmu video language]. Chuanmei 传媒 6(1): 47-48.

Gan, Chunmei, and Weijun Wang. 2015. "Uses and gratifications of social media: a comparison of microblog and WeChat." Journal of Systems and Information Technology 17(4): 351-363.

Hardaker, Claire. 2013. ""Uh.... not to be nitpicky, but... the past tense of drag is dragged, not drug. ": An overview of trolling strategies." Journal of Language Aggression and Conflict 1(1): 58-86.

Hardaker, Claire. 2017. "Flaming and trolling." Pragmatics of Social Media, eds. by C. R. Hoffmann and W. Bublitz, 493-522. Berlin: Mouton de Gruyter.

He, Ming, Yong Ge, Enhong Chen, Qi Liu, and Xuesong Wang. 2018. "Exploring the emerging type of comment for online videos: danmu." ACM Transactions on the Web (TWEB) 12(1): 1-33.

Hoffmann, Christian. 2017. "Log in: Introducing the pragmatics of social media." Pragmatics of Social Media, eds. by C. R. Hoffmann and W. Bublitz, 1-28. Berlin: Mouton de Gruyter. Johansson, Marjut. 2017. "Youtube." Pragmatics of Social Media, eds. by C. R. Hoffmann and W. Bublitz, 173-200. Berlin: Mouton de Gruyter.

Kádár, Dániel Z., Michael Haugh, and Wei-Lin Melody Chang. 2013. "Aggression and perceived national face threats in Mainland Chinese and Taiwanese CMC discussion boards." Multilingua 32(3): 343-372. 
Khan, M. Laeeq. 2017. "Social media engagement: What motivates user participation and consumption on YouTube?" Computers in Human Behavior 66: 236-247.

Kienpointner, Manfred. 2018. "Impoliteness online: Hate speech in online interactions" Internet Pragmatics 1(2): 329-351.

Lange, Patricia G. 2014. "Commenting on YouTube rants: Perceptions of inappropriateness or civic engagement?" Journal of pragmatics 73: 53-65.

Leech, Geoffrey. 2014. The Pragmatics of Politeness. Oxford: Oxford University Press.

Liu, Lili, Ayoung Suh, and Christian Wagner. 2016. "Watching online videos interactively: the impact of media capabilities in Chinese Danmaku video sites." Chinese Journal of Communication 9(3): 283-303.

Luo, Ying 罗盈. 2016. "'Shiyong yu manzu' lilun zai danmu shipin zhong de tixian - yi bilibili wang weili" "使用与满足” 理论在弹幕视频中的体现一以 bilibili 网为例 [The reflection of "Uses and gratifications" theory in danmu videos: The example of bilibili.com] Dazhongwenyi 大众文艺 15: 170-171.

Marwick, Alice E., and danah boyd. 2011. "I tweet honestly, I tweet passionately: Twitter users, context collapse, and the imagined audience." New Media \& Society 13(1): 114-133.

Pan, Yuling. 2000. Politeness in Chinese Face-to-face Interaction. Stamford, USA: Ablex.

Pan, Yuling, and Dániel Z. Kádár. 2011. Politeness in Historical and Contemporary Chinese. London, Continumm.

Qi, Xiaoxing 郄晓兴, and Hu, Lijuan 胡丽娟. 2017. "Shiyong yu manzu lilun shijiaoxia de danmu liuxing xianxiang fenxi" [使用与满足理论视角下的弹幕流行现象分析] Caixiebian 采写编 2: 137-138.

Quan-Haase, Anabel, and Alyson L. Young. 2010. "Uses and gratifications of social media: A comparison of Facebook and instant messaging." Bulletin of Science, Technology \& Society 30(5): 350-361. 
Ruggiero, Thomas E. 2000. "Uses and gratifications theory in the 21st century." Mass Communication \& Society 3(1): 3-37.

Seargeant, Philip, and Caroline Tagg (eds). 2014. The Language of Social Media: Identity and Community on the Internet. Basingstoke, UK: Springer.

Tagg, Caroline, P. Seargent, and Amy Aisha Brown. 2017. Taking Offence on Social Media. Basingstoke, UK: Springer.

Terkourafi, Marina. 2015. "Conventionalization: A new agenda for im/politeness research." Journal of Pragmatics 86: 11-18.

Wang, Jiayi. 2019. "Chinese business communication." The Routledge Handbook of Chinese Discourse Analysis, ed. by C. Shei, 325-338. London: Routledge.

Wang, Jiayi, and Charlotte Taylor. 2019. "The conventionalisation of mock politeness in Chinese and British online forums." Journal of Pragmatics 142: 270-280.

Wang, Jiayi, and Helen Spencer-Oatey. 2015. "The gains and losses of face in ongoing intercultural interaction: A case study of Chinese participant perspectives." Journal of Pragmatics 89: 50-65.

Whiting, Anita, and David Williams. 2013. "Why people use social media: a uses and gratifications approach." Qualitative Market Research: An International Journal 16(4): 362369.

Xie, Chaoqun 谢超群. 2005. Wangluo jiaoji zhong bulimao huayu de jiangou moshi ji yuyong jizhi 网络交际中不礼貌话语的建构模式及其语用机制 [Impoliteness in Computermediated Discourse: Construction Models and Pragmatic Mechanisms]. Beijing: Waiyu jiaoxue yu yanjiu chubanshe 外语教学与研究出版社.

Xie, Chaoqun, and Francisco Yus. 2018. "Introducing internet pragmatics." Internet Pragmatics 1(1): 1-12.

Xie, Chaoqun, Ziran He, and Dajin Lin. 2005. "Politeness: Myth and truth." Studies in Language 29(2): 431-461. 
Xie, Mei 谢梅, He, Ju 何炬, and Yule Feng 冯宇乐. 2014. "Dazhong chuanbo youxi lilun shijiao xia de danmu shipin yanjiu" 大众传播游戏理论视角下的弹幕视频研究 [A study of danmu videos from the perspective of the play theory of mass communication]. Xinwenjie 新 闻界 2: 37-40.

Yus, Francisco. 2017. "Contextual constraints and non-propositional effects in WhatsApp communication." Journal of Pragmatics 114: 66-86.

Zhang, Leticia Tian, and Daniel Cassany. 2019a. "The 'danmu' Phenomenon and Media Participation: Intercultural Understanding and Language Learning through' The Ministry of Time'." Comunicar: Media Education Research Journal 27(58): 19-29.

Zhang, Leticia Tian, and Daniel Cassany. 2019b. " 'The murderer is him ل' Multimodal humor in danmu video comments" Internet Pragmatics.

Zhang, Nan 张楠. 2015. "Bahejin kuanghuan lilun shiyu xia de danmu wenhua" 巴赫金狂欢 理论视域下的弹幕文化 [danmu culture from the perspective of Bakhtin's Carnival Theory]. Jinchuanmei 今传媒 23(10): 121-122.

Zhang, Wei 张玮, and Chaoqun Xie 谢朝群. 2015. "Wangluo yujingxia bulimao yuyongyu shenfen goujian fenxi - yi weibo yanjiu weili” 网络语境下不礼貌语用与身份建构分析--以 微博研究为例 [A pragmatic approach to impoliteness and identity construction in cyber context: A case analysis of Weibo]. Dandai waiyu yanjiu 当代外语研究 5: 23-28, 34 . 